\title{
Materiais curriculares educativos online como uma estratégia ao desenvolvimento profissional em matemática
}

\author{
Marcelo Almeida Bairral ${ }^{2}$
}

\begin{abstract}
Resumo: Este artigo é fruto de uma pesquisa que visa à elaboração e à disponibilização de Materiais Curriculares Educativos Online (MCEO) para o uso de docentes em suas aulas. Os dados analisados foram coletados em uma sessão presencial de pesquisa na qual os MCEO professores de matemática tiveram a oportunidade de acessar cada um dos materiais e navegar com eles. A coleta de dados foi feita mediante um roteiro de perguntas e os diários dos pesquisadores. Um dos primeiros resultados ratifica que a tarefa deve ser o ponto de partida na elaboração de um MCEO. Além de ser mais uma estratégia para o aprendizado docente, os MCEO podem constituir novas formas de obtenção online de dados na pesquisa em educação matemática interessada no desenvolvimento profissional docente. Todavia, a mera produção de MCEO não pode ser vista como responsável por melhorias na qualidade dos processos de ensino e aprendizagem matemática.
\end{abstract}

Palavras-chave: materiais curriculares educativos online, Educação Básica, formação continuada de professores, reflexão docente

\section{Online educational curriculum materials as a strategy for professional development in mathematics}

\begin{abstract}
This article stems from a research project that aims at the making and availability of online educational curriculum materials (OECM) for the use of teachers in their lessons. The analyzed data were gathered in a research off-line session during which the mathematics teachers had the opportunity to access and surf in each of the different materials. The data gathering was done through both a guideline of questions and the researchers' diaries. Some of the first results confirm that tasks have to be the starting point in the elaboration of an OECM. Besides being one more strategy for the learning of teachers, we believe that OECM can become new forms of obtaining online data for research in the education of mathematics aiming teaching professional development. Nevertheless, the availability of OECM alone cannot account for any improvement in the quality of mathematics teaching and learning processes.
\end{abstract}

Keywords: online educational curriculum materials, Basic Education, teacher training, reflection on teaching

1 Projeto no âmbito do Programa (11134) Observatório da Educação da Capes.

2 Doutor em Educação Matemática pela Universidade de Barcelona em 2002. Professor do Programa de Pós-Graduação em Educação e do Programa de Pós-Graduação em Educação em Ciências e Matemática da Universidade Federal Rural do Rio de Janeiro. E-mail: mbairral@ufrrj.br 


\section{Introdução}

A utilização de materiais curriculares (manual do professor em livros didáticos, relatos de experiência em aula, sequências didáticas, vídeos, etc.) que sejam potenciais ao aprendizado (discente ou docente) tem assumido grande atenção nas Políticas Públicas e nas pesquisas educacionais (Remillard, Herbel-Eisenmann, \& Lloyd, 2009). Todavia, a produção e a análise de materiais curriculares educativos online no desenvolvimento profissional de professores de matemática são escassas no Brasil (Oliveira \& Barbosa, 2014).

Embora seja incontestável o reconhecimento de que somos profissionais que também devem aprender constantemente, realizando-nos, inclusive, pessoalmente, continua sendo um desafio para as Instituições de Ensino construir ações que contemplem as demandas da sociedade atual e que influenciem na qualidade do trabalho formativo.

Neste artigo divulgo um Portal de MCEO e ilustro como estamos construindo MCEO para promover o desenvolvimento profissional docente em matemática. Particularmente, mostrarei resultados preliminares pautados na análise de professores a partir dos materiais que acessaram, conheceram e discutiram com a equipe de pesquisa. Minha intenção inicial é verificar que abas dos MCEO são consideradas essenciais pelos educadores.

\section{A produção e a disponibilização de materiais didáticos online para professores no Brasil: uma revisão inicial}

Atualmente, no Brasil, temos uma iniciativa de repositório apoiada pelo MEC, o Banco Internacional de Objetos Educacionais. Acontece que muitos dos objetos disponíveis nesse repositório estão em idiomas variados e também são restritivos quanto à reflexão sobre sua implementação em aula (Domingos \& Teixeira, 2011). Alguns são simulações interessantes de conceitos ou propriedades matemáticas, mas não promovem uma reflexão mais ampliada do processo de aprendizagem e de interação com o referido objeto. Tampouco oportunizam ao elaborador um maior retorno em termos de pesquisa sobre o objeto criado.

Nos estados brasileiros diferentes iniciativas públicas estão sendo efetivadas com o intuito de contribuir com a formação continuada de professores. Por exemplo, no estado do Rio de Janeiro o portal do professor global ${ }^{3}$ é uma plataforma que objetiva educação de massa individualizada nas áreas das ciências exatas, particularmente, conteúdos de Física e Matemática. Apesar de o propósito ser interessante - com a disponibilização

3 Retirado em 27 de janeiro de 2015, de http://www.professorglobal.cbpf.br/mediawiki/index.php/Página_principal. 
de vídeo-aulas, lista de exercícios, provas de nivelamento, etc. - e de o portal ainda não estar totalmente finalizado no momento da elaboração deste artigo, ele tem implícita uma perspectiva de aprendizado pautado na memorização, na resolução de exercícios para revisar ou aprender novos conteúdos, etc. (Zeppeda, 2014). Em suma, continua sendo um portal para acesso à informação e não necessariamente para aprendizagem docente a partir de situações vividas em salas de aula. Além do mais, o sítio continua priorizando o acesso e a busca individualizada de informação, sem uma maior possibilidade de interação e de geração de novas práticas a partir do disponibilizado online.

Outra iniciativa interessante no estado do Rio de Janeiro são os conteúdos digitais para o ensino e a aprendizagem de matemática e estatística (CDME) ${ }^{4}$ desenvolvidos na Universidade Federal Fluminense. No sítio dos CDME são disponibilizados softwares e experimentos educacionais e atividades de áudio. Embora exista uma riqueza temática e conteúdos matemáticos de vanguarda, com algumas possibilidades de interação e manuseio no conteúdo acessado, o portal também não fornece aos visitantes informações sobre vivências (em aulas, oficinas, etc.) e sobre descobertas feitas por meio deles.

No estado de São Paulo uma iniciativa é o portal da coleção $\mathrm{M}^{3}$ (Matemática Multimídia $)^{5}$, que contém recursos educacionais multimídia em formatos digitais desenvolvidos pela Unicamp com financiamento oficial. São mais de 350 recursos em formato de vídeos, áudios, softwares e experimentos. Embora os recursos dessa coleção abordem de forma interessante conteúdos de matemática do Ensino Médio e possam ser copiados, distribuídos gratuitamente e possam gerar outros materiais, eles também são pouco elucidativos do que acontece (ou pode acontecer) em aula.

No Estado do Paraná, na Universidade Estatual de Londrina, estão sendo elaborados casos multimídia ${ }^{6}$ para serem explorados na formação (inicial e continuada) de professores. Os casos têm como foco aulas desenvolvidas com base em uma tarefa matemática ${ }^{7}$, na perspectiva do Ensino Exploratório. Eles são constituídos por recortes de vídeos de diferentes etapas das aulas, produções escritas dos alunos, plano de aula do professor e comentários do próprio docente a respeito dessas aulas (antes e depois da aula). Na construção dos casos multimídia são utilizadas quatro etapas para a apresentação de diferentes aspectos da aula: 1) a situação antes da aula, 2) a aula em si, 3) a reflexão após a aula e 4) a aplicação na prática.

4 Retirado em 22 de janeiro de 2016, de http://www.uff.br/cdme/

5 Retirado em 30 de março de 2015, de http://m3.ime.unicamp.br

6 Retirado em 20 de janeiro de 2016, de http://rmfp.uel.br/

7 Havia três casos multimídia listados no site: Os colares, Planos de Telefonia e Brigadeiros. Algumas das tarefas usadas nos casos (por exemplo, "Cubos com autocolantes" são adaptadas da literatura, e o acesso a cada caso multimídia, no momento de finalização deste artigo, precisava ser autorizado pela equipe. O projeto conta com apoio do CNPq e é coordenado pela Profa. Márcia Cyrino. 


\section{Produção de materiais curriculares educativos para Educação Matemática: uma iniciativa no âmbito do Observatório da Capes}

Na Educação Matemática, uma iniciativa pioneira na elaboração, na análise e na disponibilização online dos materiais produzidos é o Observatório da Educação Matemática ${ }^{8}$ da Bahia (OEM/BA) e do Grupo Colaborativo em Modelagem Matemática (GCMM), desenvolvido em parceria entre a Universidade Federal da Bahia (UFBA) e a Universidade Estadual de Feira de Santana (UEFS), com apoio da Coordenação de Aperfeiçoamento de Pessoal de Nível Superior - Capes (Oliveira \& Barbosa, 2014). O OEM/BA é um desdobramento do ambiente COMMA9 (Colaboração Online em Modelagem Matemática) e tem como objetivo produzir materiais curriculares para sala de aula que promovam o compartilhamento e a discussão com outros (futuros) professores de matemática.

Os resultados do OEM/BA já têm sido divulgados. Silva, Barbosa e Oliveira (2013) analisaram a recontextualização de materiais curriculares educativos sobre modelagem matemática (MCEMM) realizada por professores iniciantes nas práticas pedagógicas. Ao observarem similaridades e diferenças na recontextualização, os autores identificaram quatro princípios agendados pelos docentes, ao moverem os MCEMM para as práticas pedagógicas: o interesse e o envolvimento dos estudantes; o conteúdo da grade curricular; a estrutura do material curricular; e a relação entre sujeitos na prática pedagógica. Esses princípios, sublinham os investigadores, "referem-se às decisões dos professores ao implementarem o ambiente de modelagem em sala de aula a partir do contato com MCEMM” (p. 64). A ação do professor, ao agendar os princípios em sala de aula, depende de regras já existentes na prática pedagógica - complementam Silva et al. (2013) - não previstas nos materiais curriculares educativos (Silva, Barbosa, \& Oliveira, 2012).

\section{Materiais curriculares educativos online: caracterização e relevância para o desenvolvimento profissional docente}

Ao caracterizar os materiais curriculares como artefatos, Brown (2009) destaca seu potencial para documentar e transmitir práticas, reforçar ideias e normas culturais, e influenciar o ensino e os professores. Em sua caracterização o autor faz um paralelo entre esses recursos e as partituras musicais. Destaca o autor que os materiais curriculares:

8 Retirado em 20 de janeiro de 2016, de http://www.educacaomatematica.ufba.br

9 Retirado em 28 de janeiro de 2015, de http://colaboracaoprofessores.blogspot.com.br 
- São representações estáticas de conceitos abstratos de tarefas dinâmicas e constituem um significado para transmitir e produzir atividade, não a tarefa por si só.

- Estão intencionados em transmitir ideias ricas e práticas dinâmicas, e o fazem mediante formas que dependem fortemente de interpretação.

- Observam um número de regras notacionais culturalmente compartilhadas, normas e convenções em suas representações, embora convenções pouco consistentemente usadas existam para materiais curriculares, mais que em partituras musicais.

- Podem refletir práticas que existem ou são usuais e, ao mesmo tempo, objetivam constituir novas práticas.

- Representam uma interface entre conhecimento, metas e valores do autor e do usuário.

- Requerem habilidade em seu uso, ou seja, são objetos inertes que se tornam vivos somente por meio da interpretação e do uso pelo usuário.

Brown (2009) ratifica que, como artefatos estáticos, os materiais curriculares documentam e transmitem práticas e também envolvem experiências dinâmicas que constituem uma combinação de planejamento, interpretação e improvisação. Da mesma forma que em partituras musicais os praticantes executam o plano de acordo com as instruções incorporadas nos artefatos, eles também se adaptam e improvisam em função de fatores locais e de sua capacidade criativa. No presente momento da nossa pesquisa, estamos analisando como os professores interpretam nossos MCEO a partir do que foi planejado pela nossa equipe, ou seja, não estamos analisando processos de recontextualização (Silva et al., 2013).

$\mathrm{O}$ interesse pela natureza da atividade de formação docente e sua influência no cotidiano profissional do educador continua assumindo relevância na pesquisa educacional, uma vez que é sabido que os professores não ensinam mecanicamente, de acordo com regras preestabelecidas, e que, dentre outras, a ação profissional docente deve estar fundamentada numa prática pedagógica crítico-reflexiva sobre o contexto e o momento em que se desenvolve a ação (Bairral \& Giménez, 2005). Desse modo, a situação na qual um professor se desenvolve profissionalmente é parte fundamental da forma como ele constrói, contextual e continuamente, um conjunto particular de conhecimentos e habilidades, que podem ser manifestados mediante diferentes estratégias formativas. Uma delas reside nos materiais curriculares educativos.

No processo de desenvolvimento profissional - formação inicial ou continuada de professores de matemática, mediado ou não pela tecnologia digital, um elemento formativo chave é que o (futuro) professor reflita metacognitivamente sobre suas 
próprias atitudes profissionais, sobre os processos de ensino e de aprendizagem, sobre a avaliação em matemática, etc. Também é importante que pondere sobre a influência de suas crenças e atitudes em relação à matemática, assim como sobre suas concepções e suas práticas pedagógicas (Santos, 1995; Santos-Wagner, 1999). Acreditamos que, com o uso de MCEO, essa reflexão também possa ser observada e potencializada.

Em sintonia com Santos (1995) e Santos-Wagner (1999), a atenção pela metacognição no processo de formação continuada a distância em matemática também foi ressaltada por Bairral e Giménez (2005). Os autores observaram dois diferentes âmbitos nos aspectos do conhecimento profissional nos quais a reflexão docente é explicitada: o de valor atribuído e o metacognitivo. No primeiro, há um processo reflexivo de caráter informativo, ou seja, aquilo que o docente mostrou conhecer ou saber a partir das atividades e busca no ambiente ou fora dele. Suas crenças, bem como a elaboração e a divulgação de planejamentos sem análise crítica prévia, também pertencem a esse domínio.

O outro âmbito, o da discussão, ilustra que o educador refletiu e mostrou integrar, em seu cotidiano profissional, as diferentes ideias e informações descobertas e discutidas colaborativamente com o coletivo profissional. Nesse processo crítico-reflexivo pode predominar um determinado aspecto ou uma reflexão, integrando mais de um deles, bem como os diferentes domínios.

No quadro 1, a seguir, ilustramos possíveis aspectos da reflexão de professores de matemática no processo interpretativo de um MCEO. 
Quadro 1: Caracterização da reflexão docente em MCEO

\begin{tabular}{|c|c|c|c|}
\hline \multirow{2}{*}{$\begin{array}{l}\text { Aspectos } \\
\text { do CCP } 9 \\
\text { a serem identificados }\end{array}$} & \multicolumn{3}{|c|}{ Reflexão e conhecimento profissional em ação } \\
\hline & $\begin{array}{c}\text { Visão e } \\
\text { confiança } \\
\text { (Drake \& } \\
\text { Sherin, 2009) }\end{array}$ & $\begin{array}{c}\text { Valor atribuído } \\
\text { (Bairral \& Giménez, 2005) }\end{array}$ & $\begin{array}{c}\text { Metacognitivo } \\
\text { (Bairral \& Giménez, 2005) }\end{array}$ \\
\hline Informação & $\begin{array}{l}\text { Ler } \\
\\
\\
\text { A } \\
\text { V } \\
\text { A } \\
\text { L }\end{array}$ & $\begin{array}{l}\text {-Busca por aba específica } \\
\text {-Caminho hipertextual livre pelo } \\
\text { MCEO } \\
\text {-Conceituação } \\
\text {-Consideração de informações } \\
\text {-Divulgação de informações } \\
\text {-Elaboração de planejamentos } \\
\text {-Explicitação de crenças } \\
\text {-Inspiração } \\
\text {-Levantamento de informações }\end{array}$ & \\
\hline Discussão & $\begin{array}{c}\mathrm{I} \\
\mathrm{A} \\
\mathrm{R} \\
\\
\text { Adaptar }\end{array}$ & & $\begin{array}{l}\text {-Análise de crenças } \\
\text {-Análise de planejamento, } \\
\text { reordenamento ou impro- } \\
\text { visação } \\
\text {-Análise pormenorizada de } \\
\text { cada aba } \\
\text {-Autocrítica da própria } \\
\text { prática } \\
\text {-Contraste de informações } \\
\text {-Discussão crítico-colabo- } \\
\text { rativa com o coletivo } \\
\text {-Explicitação e elementos } \\
\text { teóricos em seu discurso e } \\
\text { ação em aula } \\
\text {-Implementação e reorga- } \\
\text { nização de propostas } \\
\text {-Produção e publicação } \\
\text { online } \\
\text {-Revisão conceitual }\end{array}$ \\
\hline
\end{tabular}

Fonte: Elaborado a partir de Bairral e Giménez (2005, p. 10)

Segundo Bairral e Giménez (2005), enquanto os valores atribuídos possuem característica predominantemente informativa - de busca e explicitação de ideias e experiências -, no âmbito metacognitivo há contrastes, autocríticas, discussão e seu consequente aprofundamento com o coletivo. Os autores sublinharam que analisar o processo de desenvolvimento profissional, tomando elementos do discurso referenciados em sua prática, fornece-nos informações importantes sobre o conhecimento docente.

O quadro 1 aparenta ser frutífero na análise da reflexão de docentes no conhecimento de $\mathrm{MCEO}$, pois possui elementos que nos permitem analisar o aprendizado em três diferentes momentos (leitura, avaliação e adaptação), nos quais o educador

10 Conteúdo do conhecimento profissional (CCP). 
promove reflexões que lhe permitam adquirir confiança no ato de usar e inovar sua prática antes, durante ou depois do ensino (Drake \& Sherin, 2009).

\section{Os MCEO produzidos no Grupo de Pesquisa que coordeno: Gepeticem}

Ambientes virtuais, livros, softwares, Applets, objetos de aprendizagem, etc. são importantes ferramentas para a melhoria e a dinamização das aulas. E os nossos MCEO passarão a compor esse leque de alternativas didáticas para os educadores que ensinam matemática. Os MCEO são articuladores porque integram diferentes aspectos do aprendizado dos alunos (escrita, vídeos, respostas, dúvidas) e são fruto de implementações reais em sala de aula. Eles possuem uma estrutura navegacional simples e poderão ser utilizados por professores em qualquer parte do nosso estado e país.

Os materiais curriculares educativos online disponibilizados em nosso Portal ${ }^{11}$ são frutos de um projeto no âmbito do Observatório da Educação Capes (2013/2015). Eles têm como objetivo contribuir para que o professor possa se inspirar e construir alternativas inovadoras com diferentes tecnologias para as suas aulas. Portanto, nossos MCEO estão focados no aprendizado do professor em exercício ou do futuro docente.

Os $\mathrm{MCEO}^{12}$ são oriundos do nosso trabalho em Escolas Públicas (Municipais, Estaduais ou Federais). São autores dos MCEO os futuros professores ou os docentes $^{13}$ (da Educação Básica ou do Ensino Superior) que participam de nossos projetos e, consequentemente, integram o nosso grupo de pesquisa. A maioria dos MCEO vem da seleção posterior do seu elaborador, de alguma de suas vivências com a implementação (individual ou coletiva) de uma sequência de atividades em situações reais de ensino (sala de aula, oficina com professores ou futuros educadores) ${ }^{14}$.

Com a publicização de MCEO objetivamos ampliar a possibilidade de utilização e de reflexão docente sobre o que podemos aprender com cada material disponi-

11 http://www.gepeticem.ufrrj.br/portal/categoria/materiais-curriculares/

12 Nossos MCEO foram inspirados no ambiente Comma (http://argo.uefs.br/comma/). Agradeço aos colegas Andreia Maria Pereira de Oliveira (UFBA) e Jonei Cerqueira Barbosa (UFBA) pela ideia e pela parceria neste nosso projeto.

13 Múltiplas foram as formas de lidar com a informática nas escolas públicas partícipes. Havia estabelecimentos com poucos equipamentos, mas sem Internet; outros com um laboratório melhor, mas com restrições legais para uso de telefones celulares, etc.; escola com laboratório e conexão boa com a Internet, dentre outras.

14 Em versões mais recentes (a partir de 2016) dos MCEO objetivamos criar a aba "Apostila", no caso de o material ser fruto de uma dessas atividades. A disponibilização completa da apostila pode ser mais um orientador didático para o professor. Para os MCEO que não usam softwares ou algum outro tipo de recurso informático, pensamos elaborar e disponibilizar tutoriais sobre o manuseio do programa, etc. 
bilizado. Também estamos oferecendo aos educadores oportunidade de interagir online sobre o MCEO. Cada MCEO é composto de seis links (abas) com finalidades próprias, a saber:

Quadro 2: Abas de um MCEO

\begin{tabular}{|c|c|c|}
\hline Aba & Conteúdo & O que contém \\
\hline Apresentação & \multirow{5}{*}{$\begin{array}{l}\text { Elaborado, revisado e } \\
\text { postado pela equipe do } \\
\text { projeto }\end{array}$} & $\begin{array}{l}\text { Motivação e apresentação da atividade e seu propósito } \\
\text { principal. }\end{array}$ \\
\hline Tarefa & & $\begin{array}{l}\text { Enunciado da tarefa com objetivos, esclarecimentos, } \\
\text { etc. }\end{array}$ \\
\hline Resposta(s) & & $\begin{array}{l}\text { Exemplos (escritos, imagens, telas de computador, } \\
\text { etc.) de resposta(s) dada(s) pelos alunos para a } \\
\text { atividade. }\end{array}$ \\
\hline Narrativa $^{14}$ & & $\begin{array}{l}\text { Uma reflexão do autor sobre parte da atividade } \\
\text { implementada. }\end{array}$ \\
\hline Vídeo(s) & & $\begin{array}{l}\text { Edição de fragmentos de vídeos sobre alunos } \\
\text { trabalhando (ou interagindo) na atividade em foco. }\end{array}$ \\
\hline Fórum & \multirow{3}{*}{ Postagem livre ${ }^{15}$} & $\begin{array}{l}\text { Espaço para interação e troca de ideias em tempo } \\
\text { diferido (assíncrono). }\end{array}$ \\
\hline Chat & & $\begin{array}{l}\text { Espaço para interação síncrona (tempo real). Você } \\
\text { poderá interagir com algum colega que esteja online } \\
\text { conhecendo o material. }\end{array}$ \\
\hline Comentários & & $\begin{array}{l}\text { Espaço aberto para opiniões e postagens variadas, } \\
\text { sugestões, solicitação de esclarecimentos, etc. }\end{array}$ \\
\hline
\end{tabular}

Fonte: http://www.gepeticem.ufrrj.br/portal/categoria/materiais-curriculares/

Nossos materiais curriculares estão focados, prioritariamente, na educação geométrica, seja com recursos mais convencionais (papel e lápis, Tangram, etc.), seja com suportes informáticos mais recentes (como os dispositivos touchscreen). Quanto à temática, optamos por explorar conteúdos desde temas pouco presentes (poliedros, seções planas, etc.) nas aulas de matemática a conteúdos mais frequentes (operações numéricas, semelhança, etc.). Todos os MCEO são recortes de situações implementadas naturalmente em aula por, pelo menos, um dos integrantes do nosso grupo de pesquisa. A seguir, listo os títulos dos $28 \mathrm{MCEO}$ produzidos no Gepeticem até o momento de finalização deste artigo.

15 No atual momento de análise estamos vendo a narrativa como um instrumento de reflexão docente que, como tal, constitui a teia reflexiva do MCEO.

16 Para evitar postagens com conteúdo indevido, estamos implementando um filtro. Esse processo tem levado um tempo e, com isso, ainda não dispomos dos dados provenientes dessas abas. 
Quadro 3: Títulos ordenados dos 28 MCEO elaborados e disponibilizados online

1. Batendo na mesma tecla

2. Bissectograma

3. Como cortar o bolo: Explorando as regiões do círculo

4. Construindo e analisando funções em planilhas eletrônicas

5. Construindo e analisando gráficos do Îndice de Desenvolvimento Humano

6. Construindo gráfico da função linear no GeoGebra

7. Construindo gráfico da função quadrática no GeoGebra

8. Cortando o cubo

9. CTRL C, CTRL V no Paintbrush

10. Exercitando a memória da calculadora

11. Experimentando gráficos

12. Flor de polígonos

13. GeoGebra: Função do 2o grau

14. Geometrizando sistemas lineares

15. Malha, triângulo e estrela

16. Mãos, pontos e barbante

17. Mexendo nos palitos e explorando a rigidez do triângulo

18. Mexendo nos palitos e explorando formas criadas

19. Navegando no GeoGebra

20. O software SketchUp

21. Observando, descrevendo e montando

22. Pedalando no GeoGebra

23. Pontos notáveis no triângulo

24. Retângulos malcomportados

25. Seções em cubos no GeoGebra 3D

26. Será que é quadrado? Trabalhando geometria no Sketchometry

27. Uma volta na circunferência. Quem é Pi?

28. Varignon touchscreen no construtor geométrico

Fonte: Portal dos MCEO na Internet ${ }^{17}$

Cada MCEO aborda um aspecto de determinado conteúdo matemático. O usuário também poderá baixar livremente o conteúdo de cada aba como um documento para leitura e reflexão no modo off-line. O conteúdo das abas em azul é postado por nossa equipe, e as abas em laranja são espaços abertos de interação assíncrona (fórum e comentários) ou síncrona (chat), conforme é apresentado na Figura 1.

Figura 1: Abas de cada MCEO

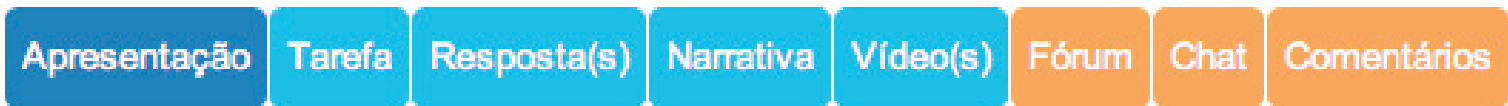

Para a elaboração dos MCEO, utilizamos os seguintes procedimentos: planejamento prévio e seleção - discussão no coletivo do projeto - (re)elaboração - revisão - implementação - análise - revisão - publicação no Portal. Esse processo de

17 http://www.gepeticem.ufrrj.br/portal/categoria/materiais-curriculares/ 
elaboração é também uma fonte de coleta de dados na pesquisa. Nossa análise está sendo conduzida em quatro momentos, a saber:

Quadro 4: Momentos de análise

\begin{tabular}{|c|c|c|c|}
\hline Momento & Sujeitos & $\begin{array}{l}\text { Instrumentos de coleta } \\
\text { de dados }\end{array}$ & Foco de análise \\
\hline $\begin{array}{l}\text { 1. Elaboração de } \\
\text { sequência didática } \\
\text { (grupo de pesquisa) }\end{array}$ & $\begin{array}{l}\text { Professores da } \\
\text { Educação Básica } \\
\text { (EB) e equipe de } \\
\text { pesquisa }\end{array}$ & $\begin{array}{l}\text {-apostilas } \\
\text {-diários dos } \\
\text { pesquisadores }\end{array}$ & $\begin{array}{l}\text { Elaboração, } \\
\text { criatividade, } \\
\text { autonomia, } \\
\text { sequenciamento (Bairral \& } \\
\text { Giménez, 2005; Silva et al., } \\
\text { 2012, 2013) }\end{array}$ \\
\hline $\begin{array}{l}\text { 2. Identificação } \\
\text { de melhorias no } \\
\text { aprendizado de } \\
\text { professores }\end{array}$ & Professores da EB & $\begin{array}{l}\text {-resposta de atividades } \\
\text { nas implementações } \\
\text { (oficinas) } \\
\text {-roteiros de perguntas } \\
\text {-observação participante } \\
\text {-acesso online aos MCEO } \\
\text {-diários dos } \\
\text { pesquisadores } \\
\end{array}$ & \multirow[t]{2}{*}{\begin{tabular}{|l|} 
Interpretação focada em \\
indícios de aprendizado \\
(Bairral \& Giménez, 2005)
\end{tabular}} \\
\hline $\begin{array}{l}\text { 3. Observação e } \\
\text { acompanhamento } \\
\text { sistemático }\end{array}$ & Professores da EB & $\begin{array}{l}\text {-portfólios eletrônicos } \\
\text { individuais } \\
\text {-diários dos } \\
\text { pesquisadores }\end{array}$ & \\
\hline $\begin{array}{l}\text { 4. Contraste e } \\
\text { metanálise }\end{array}$ & $\begin{array}{l}\text { Professores da } \\
\text { Educação Básica } \\
\text { (EB) e equipe de } \\
\text { pesquisa }\end{array}$ & $\begin{array}{l}\text {-M1+M2+M3 } \\
\text {-interações online nos } \\
\text { MCEO acessados }\end{array}$ & $\begin{array}{l}\text { Interpretação, improvisação, } \\
\text { planejamento, uso em aula } \\
\text { (Brown, 2009; Drake \& } \\
\text { Sherin, 2009; Silva et al., } \\
\text { 2012, 2013) } \\
\end{array}$ \\
\hline
\end{tabular}

Fonte: Elaboração do autor

Neste artigo ilustro resultados prévios para o segundo momento de análise. Os dados foram coletados em uma sessão de pesquisa na qual os MCEO eram a principal fonte de coleta de dados. Os docentes tiveram a oportunidade de acessar e navegar em cada um dos MCEO e, para cada um, havia um roteiro de perguntas a ser respondido (Bairral et al., 2014). Além das respostas para o roteiro, usamos como fonte de dados os diários de campo dos pesquisadores envolvidos na sessão (presencial) de pesquisa, que durou aproximadamente três horas. Foram oito docentes, todos licenciados em matemática, sendo que sete deles atuavam no Ensino Fundamental ou Médio.

Veremos alguns resultados preliminares, organizados em três focos de análise, a saber: (i) opinião dos docentes sobre a importância do conteúdo das abas de um MCEO, (ii) sobre a conceituação de polígonos em MCEO analisados e (iii) sobre a caracterização da reflexão docente na análise dos MCEO. 


\section{Resultados preliminares}

\section{Sobre a importância das abas para os docentes}

Quando questionados sobre qual das abas atraiu mais a sua atenção e qual delas considerava indispensável, os sete educadores responderam:

Quadro 5: Respostas dos docentes sobre a aba de interesse

1. Tarefas, respostas e vídeo. Considero a tarefa indispensável.

2. Aba tarefa $\underline{18}^{18}$ como indispensável e a aba apresentação como mais chamativa.

3. A aba "tarefa" obviamente é indispensável. Porém considero a "narrativa" a mais interessante.

4. A que mais me atraiu foi a aba "tarefa", mas as outras abas também são indispensáveis.

5. A aba "tarefa”. E também a considero como indispensável, pois é onde fica problematizado.

6. O vídeo. Considero que o fórum e comentários são abas que permitirão uma troca com as experiências dos colegas, portanto indispensáveis.

7. Tarefa e narrativa. Acredito que a apresentação.

Fonte: Elaboração do autor

A aba tarefa foi a que despertou a atenção de todos os professores. Isso era esperado, pois um material curricular educativo parte de uma situação concreta de aula, e os educadores geralmente buscam conhecer sugestão de atividades para uso em sua prática (Silva et al., 2013). Todavia, alguns profissionais ressaltaram a relevância de outras abas, como apresentação (P2 e 8), narrativa (P3 e 8), vídeo (P1 e 6), fórum (P6) e comentários (P6). O P4 enfatiza a importância de todas as abas.

Dar voz ao professor é sempre importante, pois não nos interessa construir um portal esteticamente maravilhoso, mas que não seja efetivo no aprendizado de quem o acessa com o intuito de inovar e aprender. Além do mais, um MCEO tem um grande diferencial de um material curricular convencional: a sua multiplicidade de formatos. Essa característica, embora tenha entraves de ordem informática para ser implementada, precisa ser efetivada.

Com o intuito de continuar analisando a interpretação (Brown, 2009) do professor para o MCEO de modo a obter informações sobre a efetividade desses materiais no aprendizado docente, a seguir ilustramos parte da reflexão de dois pesquisados em uma das atividades do roteiro de perguntas utilizado: 
Quadro 6: Roteiro para análise dos MCEO (16, 17 e 19 listados no Quadro 3)

(a) Escreva como você define um polígono para seus alunos. Agora dê três exemplos de polígonos (por escrito ou desenho).

(b) Acesse e navegue por cada uma das abas dos seguintes materiais: Mexendo nos palitos e explorando as formas criadas, Mexendo nos palitos e explorando a rigidez do triângulo e Mãos, pontos e barbante.

(c) Faça alguma observação sobre as abas ${ }^{19}$.

(d) Agora reescreva a sua definição de polígono. Você considera que este material enriquece a definição que você apresentou na letra a? Comente.

Fonte: Elaboração da equipe do projeto

\section{Sobre o MCEO e a conceituação de polígonos ${ }^{20}$ no aprendizado docente}

Escolhemos esses três MCEO porque eles abordam um conceito familiar aos educadores, o de polígonos. O quadro 7 ilustra dois professores (P4 e P7) explicitando reflexões de natureza conceitual e didática (tipo de atividade ou sequenciação) a partir do roteiro de questionamentos proposto (Bairral, Vianna, Honorato, \& Settimy, 2014).

Quadro 7: Roteiro de pergunta 2

\begin{tabular}{|c|c|c|c|c|}
\hline $\begin{array}{c}\text { Atividade 2: Sobre o MCEO } \\
\ldots\end{array}$ & Professor 4 (P4) & Reflexão P4 & Professor 7 (P7) & $\begin{array}{l}\text { Reflexão } \\
\text { P7 }\end{array}$ \\
\hline $\begin{array}{l}\text { a) Escreva como você } \\
\text { define um polígono para } \\
\text { seus alunos. Agora dê três } \\
\text { exemplos de polígonos (por } \\
\text { escrito ou desenho). }\end{array}$ & $\begin{array}{l}\text { P4a) "Figuras planas com } \\
\text { lados de mesma medida } \\
\text { ou não onde os vértices } \\
\text { representam o ponto de } \\
\text { encontro dos lados". }\end{array}$ & conceitual & $\begin{array}{l}\text { P7a) "É uma } \\
\text { forma geométrica } \\
\text { plana limitada por } \\
\text { segmentos de reta". }\end{array}$ & conceitual \\
\hline $\begin{array}{l}\text { b) Acesse e navegue } \\
\text { por cada uma das } \\
\text { abas dos seguintes } \\
\text { materiais: Mexendo nos } \\
\text { palitos e explorando as } \\
\text { formas criadas, Mexendo } \\
\text { nos palitos e explorando a } \\
\text { rigidez do triângulo e Mãos, } \\
\text { pontos e barbante. Faça } \\
\text { alguma observação sobre as } \\
\text { abas. }\end{array}$ & $\begin{array}{l}\text { P4b) "Foi abordado de } \\
\text { forma simples e clara, fácil } \\
\text { para o entendimento do } \\
\text { aluno, também direciona } \\
\text { o professor em sua aula". }\end{array}$ & $\begin{array}{l}\text { didática } \\
\text { (sequência) }\end{array}$ & $\begin{array}{l}\text { P7b) “As duas } \\
\text { primeiras atividades } \\
\text { são 'controladas' } \\
\text { o aluno recebe as } \\
\text { formas 'prontas' para a } \\
\text { exploração. A terceira } \\
\text { atividade coloca o } \\
\text { aluno como sujeito, } \\
\text { pois as construções } \\
\text { irão depender do } \\
\text { grupo colaborativo”. }\end{array}$ & \\
\hline $\begin{array}{l}\text { c) Agora reescreva a sua } \\
\text { definição de polígono. Você } \\
\text { considera que este material } \\
\text { enriquece a definição que } \\
\text { você apresentou na letra } a \text { ? } \\
\text { Comente. }\end{array}$ & $\begin{array}{l}\text { P4c) "Eu acrescentaria à } \\
\text { definição anterior o fato } \\
\text { de que os pontos que } \\
\text { saem das extremidades } \\
\text { dos segmentos de reta } \\
\text { devem estar num mesmo } \\
\text { plano. Sim, fica evidente } \\
\text { que o material enriquece } \\
\text { minha definição anterior". }\end{array}$ & conceitual & $\begin{array}{l}\text { P7c) "Com absoluta } \\
\text { certeza as atividades } \\
\text { são enriquecedoras } \\
\text { para a construção dos } \\
\text { conceitos relativos } \\
\text { ao ensino deste } \\
\text { conteúdo". }\end{array}$ & $\begin{array}{l}\text { didática } \\
\text { (tipo de } \\
\text { atividade) } \\
\text { atividade }\end{array}$ \\
\hline
\end{tabular}

Fonte: Elaboração do autor

19 Como realizei uma análise de abas na seção anterior, optei aqui por focar o aspecto conceitual do MCEO.

20 Para obter mais informações sobre as situações concretas de aula que geraram esses MCEO, ver Santos e Bairral (2015). 
As transcrições do quadro 7 mostram que os docentes aparentaram aprender (P4c e P7c) no acesso ao material. Acreditamos que, com as suas três abas interativas (fórum, chat e comentários), os MCEO permitirão aos docentes socializarem conhecimentos e experiências variadas, ampliando ainda mais o potencial multiusuário do material.

\section{Sobre o MCEO e a caracterização da reflexão docente}

No quadro 8, seguinte, expomos dois momentos (leitura e avaliação) na reflexão dos docentes nos MCEO analisados.

Quadro 8: Caracterização da reflexão docente em MCEO

\begin{tabular}{|c|c|c|}
\hline Aspectos & \multicolumn{2}{|c|}{ Conhecimento profissional em reflexão nos MCEO } \\
\hline do $\mathrm{CCP}^{20}$ & \multicolumn{2}{|l|}{ Valor atribuído } \\
\hline \multirow{2}{*}{ Informação } & $\begin{array}{l}\text {-Conceituação } \\
\text {-Inspiração } \\
\text {-Consideração de informações }\end{array}$ & $\begin{array}{l}\text { "Eu acrescentaria à definição anterior o fato de } \\
\text { que os pontos que saem das extremidades dos } \\
\text { segmentos de reta devem estar num mesmo pla- } \\
\text { no. Sim, fica evidente que o material enriquece } \\
\text { minha definição anterior". (P4c) }\end{array}$ \\
\hline & & $\begin{array}{l}\text { “Com absoluta certeza as atividades são enrique- } \\
\text { cedoras para a construção dos conceitos relativos } \\
\text { ao ensino deste conteúdo". (P7c) }\end{array}$ \\
\hline
\end{tabular}

Fonte: Elaboração do autor

Podemos observar os valores atribuídos pelos docentes, ao refletirem em âmbito informativo. Os educadores, ao considerarem as informações disponíveis no material, realizaram esclarecimentos conceituais sobre a definição de polígono (P4c e P7c). Essas reflexões informativas aparentam ser pouco elucidativas do que se efetiva em aula.

A análise sobre a adaptação e o uso em aula demanda tempo. Um contraste entre os textos transcritos nos quadros 5 e 6 suscita-nos um questionamento de que os momentos avaliativos ou adaptativos (Drake \& Sherin, 2009) podem ser frutíferos para reflexões de cunho metacognitivo. Portanto, a confiança, as diferentes formas de implementação e a reflexão sobre o ocorrido (antes, durante ou depois do ensino) em sua aula será algo observável em análises posteriores.

Conforme Bairral e Gimenez (2005), os processos de socialização de experiências, a predisposição para aprender e o comprometimento para intervir continuamente a partir das colocações de todo o coletivo podem ser contribuições

21 Conteúdo do conhecimento profissional (CCP). 
singulares em cada âmbito (informativo ou metacognitivo) de reflexão. Esse será um de nossos olhares futuros para os MCEO com as abas chat, fórum e comentários. Além do mais, alguns dos nossos MCEO ainda possuem restrições de áudio, vídeo ou de ilustração gráfica. Estamos trabalhando para aprimorar essas limitações e, dessa forma, aprimorar também nossa análise.

\section{Reflexões (in)conclusivas}

Neste artigo ilustrei que o uso de MCEO pode promover o aprendizado de professores em exercício ou em formação inicial. Analisar como e por que os docentes usam os MCEO em suas aulas é importante tanto para a (re)elaboração do material pela equipe de pesquisa como para construir estratégias efetivas de apoio ao professor em sala de aula (Drake \& Sherin, 2009). A aba tarefa é a essencial em um MCEO, resultado que ratifica a ideia de Oliveira e Barbosa (2014) de que ela deve ser o ponto de partida na construção de um MCEO.

A análise preliminar discutida neste artigo instiga nosso grupo de pesquisa a observar futuramente se reflexões de cunho metacognitivo emergem apenas em momentos nos quais o professor avalia ou adapta o material para ser usado em sua aula. A leitura do material pode ser um tempo propício para a emergência de valores atribuídos, com caráter mais informativo e não muito elucidativos do que realmente acontece na aula. Cabe mais análise, pois ainda não analisamos os docentes implementando os materiais. Talvez, inclusive, as abas interativas (fórum, chat e comentários) possam, ao longo de um tempo maior, trazer informações mais variadas que nos permitam analisar a emergência (ou não) de uma discussão coletiva pormenorizada e com caraterística metacognitiva.

Considerando que uma pesquisa no âmbito da informática educativa deve usar ou gerar novos recursos tecnológicos, também pensamos que os MCEO poderão constituir um novo tipo de instrumento para coleta e análise de dados no campo educacional com tecnologias digitais. Portanto, a disseminação online dessa proposta com acesso livre pelos educadores e, futuramente, com a possibilidade de que um MCEO se torne um recurso educacional aberto (Santana, Rossini, \& Pretto, 2012) - com direito, além da consulta, à elaboração ou reformulação e à postagem de um MCEO autoral -, poderá vir a ser uma grande contribuição de um projeto desta natureza ao desenvolvimento profissional docente em nosso país.

Outra possibilidade de disseminação deste tipo de projeto será o uso de MCEO em cursos de formação inicial de professores. Docentes que atuam em Prática de Ensino, Estágio Supervisionado ou atividade similar muitas vezes possuem dificuldades para a filmagem de atividades de regência dos licenciandos. Além dessa possibilidade de observar o que pode acontecer em determinada aula com fragmentos de vídeo, 
um MCEO contém outros elementos (narrativa, tipos de respostas dadas, tarefa, etc.) que podem enriquecer o cenário analítico de aulas e demais vivências formativas nas licenciaturas. Assim, um portal de acesso livre a MCEO pode tornar-se importante recurso para potencializar a aprendizagem dos futuros educadores matemáticos.

Cabe, portanto, ressaltar que não serão apenas os materiais ou outros tipos de produtos educativos que promoverão mudanças qualificativas nos processos de ensino e aprendizagem. Ainda que uma dinâmica de desenvolvimento profissional implique criatividade, coletividade, colaboração e cumplicidade profissional, dentre outros, é necessário pensarmos em políticas públicas que deem autonomia às escolas e aos professores e também invistam em melhorias das condições infraestruturais das escolas e de trabalho do professor. Como pensar em inovação em um estabelecimento de ensino que possui na porta do seu único laboratório o aviso seguinte?

Figura 2: Aviso colocado na porta do laboratório de informática de uma Escola Pública

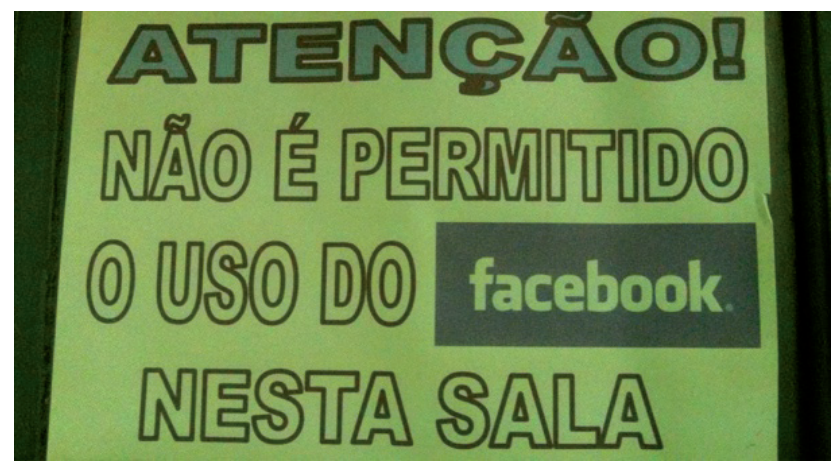

Fonte: Foto do autor

Não estou aqui incentivando o uso deliberado de redes sociais ou de qualquer outro suporte tecnológico na escola. Todavia, a análise realizada por Guimarães (2015) ressalta que, com a tentativa de inserção da tecnologia no ensino, acentuamse ainda mais as dificuldades de vivenciar e promover mudanças na prática docente, uma vez que entraves de natureza informática (escassez de equipamentos para alunos, sistemas operacionais incompatíveis, indisponibilidade ou restrição de conexão, etc.), falta de recursos humanos para apoio técnico e restrições legais ${ }^{22}$ ampliam o $^{-}$ leque de dificuldades a serem vivenciadas pelos educadores no planejamento e na execução de uma inovação em aula com tecnologia digital.

Embora o uso que o professor faça para materiais curriculares educativos dependa de regras já existentes em sua prática pedagógica (Silva et al., 2013), estamos

22 Acessar, por exemplo, o link da Lei 5453/2006, que dispõe sobre a proibição do uso de telefone celular nas escolas estaduais do estado do Rio de Janeiro. Retirado em 23 de janeiro de 2016, dehttp://alerjlnı.alerj. rj.gov.br/CONTLEI.NSF/c8aaogooo25feef6032564ecoo6odfff/98coae15f7fia1e6832575c3005abe88?OpenDocument 
investigando como docentes de matemática se apropriam dos MCEO e buscam inovar suas práticas. Particularmente, queremos observar como as possibilidades de interação e colaboração online podem enriquecer o aprendizado dos educadores e fornecer pistas aos pesquisadores sobre como usar esse material em suas aulas. Para isso, o acompanhamento sistemático de formas de uso e apropriação na recontextualização (Silva et al., 2013) pode ser um caminho analítico promissor. Enfim, ainda temos muito para trilhar com os MCEO na pesquisa em educação matemática no Brasil!

\section{Referências}

Assis, A. R. de (2016). Alunos do Ensino Médio trabalhando no GeoGebra e no Geometric Constructer: mãos e rotAções em touchscreen. Dissertação de Mestrado em Educação/PPGEduc, Universidade Federal Rural do Rio de Janeiro, Seropédica.

Bairral, M. A., \& Giménez, J. (2005). Momentos reflexivos e metacognição na teleformação continuada em Matemática. Quadrante, 14(2), 3-23.

Bairral, M., Vianna, M., Honorato, V., \& Settimy, T. (2014). O uso de materiais curriculares educativos online na formação continuada de professores de matemática. In 6 EEMAT-RJ, Niterói. Retirado em 5 de junho de 2015. http://www.sbemrj.com.br/p/anais.html

Brown, M. W. (2009). The teacher-tool relationship: Theorizing the design and use of curriculum materials. In J. T. Remillard, B. A. Herbel-Eisenmann, \& G. M. Lloyd (Eds.), Mathematics teachers at work: Connecting curriculum materials and classroom instruction (pp. 17-36). New York: Routledge.

Domingos, A., \& Teixeira, P. C. (2011). Os materiais electrónicos que acompanham os manuais e a aula de matemática. Educação e Matemática, 115, 64-66.

Drake, C., \& Sherin, M. G. (2009). Developing curriculum vision and trust: Changes in teachers' curriculum strategies. In J. T. Remillard, B. A. Herbel-Eisenmann, \& G. M. Lloyd (Eds.), Mathematics teachers at work: Connecting curriculum materials and classroom instruction (pp. 321-337). New York: Routledge.

Guimarães, W. N. (2015). Um estudo sobre a inserção tecnológica na formação continuada de docentes de matemática. Dissertação de Mestrado em Educação/PPGEduc, Universidade Federal Rural do Rio de Janeiro, Seropédica.

Izar, S. B. (2014). Explorando o conceito de Homotetia com alunos do Ensino Fundamental: uma abordagem com aplicativos dinâmicos inspirada na cultura visual. Dissertação de Mestrado em Educação/PPGEduc, Universidade Federal Rural do Rio de Janeiro, Seropédica.

Marques, W. da S. (2013). Calculadora em sala de aula: um estudo focado no aprendizado de alunos do Ensino Médio Profissionalizante. Dissertação de Mestrado em Educação/PPGEduc, Universidade Federal Rural do Rio de Janeiro, Seropédica.

Oliveira, A. M. P., \& Barbosa, J. C. (2014). A produção de materiais curriculares educativos em grupos colaborativos. In M. A. Gonçalves Júnior, E. M. Cristovão, \& R. C. R. Lima (Eds.), Grupos colaborativos e de aprendizagem do professor que ensina matemática: repensar a formação de professores é preciso! (pp.118-126). Retirado em 10 de março de 2015, de https://docs.google.com/file/d/0BzM7EA04taCJeVczaHFDZ3h4WlU/edit 
Oliveira, G. W. B. de (2016). Épura em vídeo: desenvolvimento e uso de um aplicativo para o trabalho com geometria descritiva. Dissertação de Mestrado em Educação/PPGEduc, Universidade Federal Rural do Rio de Janeiro, Seropédica.

Remillard, J. T., Herbel-Eisenmann, B.A., \& Lloyd, G. M. (Eds.). (2009). Mathematics teachers at work: Connecting curriculum materials and classroom instruction. New York: Routledge.

Santana, B., Rossini, C., \& Pretto, N. de L. (2012). Recursos educacionais abertos: práticas colaborativas e políticas públicas. São Paulo: Casa da Cultura Digital; Salvador: EDUFBA.

Santos, R. T., \& Bairral, M. A. (2015). Aspectos emergentes na construção do conceito de polígono por alunos do $6^{\circ}$ ano de uma escola pública. Vidya, 35(1), 1-26.

Santos, V. M. P. dos. (1995) Matemática: conhecimento, concepções e consciência metacognitiva de professores em formação e em exercício. In Seminário Internacional (pp.117-133). Instituto de Matemática/Universidade Federal do Rio de Janeiro, Rio de Janeiro.

Santos-Wagner, V. M. (1999). The development of teachers' awareness of the process of change: Brazilian experiences with practising teachers. In N. Ellerton (Ed.), Mathematics teacher development: International perspectives (pp. 217-256). Australia: Meridian Press.

Silva, M. S., Barbosa, J. C., \& Oliveira, A. M. P. (2012). O sequenciamento do ambiente de modelagem matemática a partir do contato com materiais curriculares educativos. Acta Scientiae, 14(2), 240-259.

Silva, M. S., Barbosa, J. C., \& Oliveira, A. M. P. (2013). Materiais curriculares educativos sobre modelagem matemática e a recontextualização pedagógica operada por professores iniciantes. Revista Iberoamericana de Educación Matemática UNIÓN, 34, 44-67.

Zeppeda, V. (2014). Pelos caminhos da educação no mundo virtual. Rio Pesquisa, 29, 32-35.

Submetido em: 24/01/2016

Aceito em: 01/03/2016 